\title{
Predictors of University Student Satisfaction with Life, Academic Self-Efficacy, and Achievement in the First Year
}

\author{
Gabrielle Wilcox \\ University of Calgary \\ David Nordstokke \\ University of Calgary
}

\begin{abstract}
Understanding personal factors that contribute to university student satisfaction with life is important in order to determine how we can better prepare students for the transition to post-secondary education and support them during this transition. This study examined predictors of university student satisfaction with life, academic self-efficacy, and self-reported academic achievement in their first year of university. First-year students $(n=66)$ completed selfreport measures of academic achievement, university well-being, satisfaction with life, personality, and mental health. A linear regression analysis approach was applied to the data. Results indicated that academic satisfaction and school connectedness predicted satisfaction with life but that academic self-efficacy and college gratitude did not, conscientiousness predicted academic self-efficacy, college well-being predicted self-reported achievement, and anxiety predicted achievement but depression did not. This study highlights the importance of understanding the personal factors that influence well-being and achievement during the transition to university.
\end{abstract}

\section{Résumé}

Il est important de comprendre les facteurs personnels qui contribuent à la satisfaction des étudiants universitaires à l'égard de la vie afin de mieux les préparer à la transition vers l'éducation postsecondaire et les soutenir pendant cette transition. Cette étude a examiné les indicateurs de satisfaction 
des étudiants universitaires à l'égard de la vie, l'auto-efficacité académique, et la perception de leur rendement scolaire durant leur première année universitaire. Des étudiants de première année $(n=66)$ ont complété des mesures d'auto-évaluation sur leurs résultats académiques, le bien-être, leur satisfaction à l'égard de la vie, la personnalité et la santé mentale. Les données ont été analysées par l'approche d'analyse de régression linéaire. Les résultats ont indiqué que la satisfaction et la connectivité au milieu scolaire ont prédit une satisfaction à l'égard de la vie et que l'auto-efficacité académique et la gratitude du milieu scolaire ne l'ont pas prédit. Le souci du travail bien fait a prédit l'auto-efficacité académique. Le bien-être dans le milieu postsecondaire a prédit le sentiment d'accomplissement, et l'anxiété a prédit la réussite, mais pas la dépression. Cette étude souligne l'importance de comprendre les facteurs personnels qui influencent le bien-être et la réussite au cours de la transition universitaire.

\section{Introduction}

Earning a post-secondary degree is an important achievement for later job opportunities. Unfortunately, in the United States, less than half of students who enter university graduate (Knapp, 2007), highlighting the impfortance of exploring student experiences during the transition to university. The process of transition to university is both challenging for many students and important for completing their university degrees, as student perceptions of the transition experience and the coping strategies they employ predict future adjustment and academic success (Perera, McIlveen, \& Oliver, 2015; Woosley $\&$ Miller, 2009). The move to university requires many adjustments, including adapting to increased personal responsibility for academic work and self-care and increased freedom (Blair, 2017; Credé \& Niehorster, 2012; Fromme, Corbin, \& Kruse, 2008; Smith \& Zhang, 2008; Venezia \& Jaeger, 2013). These changes in freedom and responsibility impact student well-being and achievement (Burke, Ruppel, \& Dinsmore, 2016; Richardson, Abraham, \& Bond, 2012; Stamp et al., 2015). To determine how to support success during this transition, in the areas of both well-being and academic success, it is important to examine the factors that impact these outcomes.

\section{Students' Well-Being}

Multiple terms are related to the general idea of happiness. Two terms that researchers often use to examine the general idea of happiness are subjective well-being and life satisfaction. Subjective well-being is defined as the combination of relatively high levels of positive affect, relatively low levels of negative affect, and relatively high levels of life satisfaction (Diener, Lucas, \& Oishi, 2005). Life satisfaction is a cognitive assessment of the quality of one's life overall (Suldo, Riley, \& Shaffer, 2006). However, some researchers use happiness as a synonym for subjective well-being (Oishi, Diener, \& Lucas, 2007), highlighting the nebulous nature of these concepts.

There are three primary theoretical orientations for what leads to happiness, which emphasize fulfilling goals, engaging in meaningful activity, and genetic predisposition (Diener et al., 2005). Goal fulfillment suggests that happiness requires action toward gaining a specific outcome (Diener et al., 2005; Proctor, Linley, \& Maltby, 2009). While 
meaningful activity also involves action, the pleasure attained from the action itself is more important than the outcome (Diener et al., 2005). Finally, genetic predisposition proposes that while there is day-to-day variation in individual ratings of happiness, there is a level of stability suggesting that it is both a state and a trait (Diener et al., 2005).

\section{Connectedness}

Social connectedness, the subjective experience of interpersonal closeness (Lee \& Robbins, 1995), is important in fostering a successful transition to university. Studentathletes in university demonstrated significantly higher levels of connectedness than nonathletes (Armstrong \& Oomen-Early, 2009), indicating the importance of structured opportunities for engagement. Frequent, casual interactions with classmates also increase university students' reporting of happiness and sense of belonging, suggesting that not only are close relationships important but that casual interactions contribute to feelings of connectedness and belonging (Sandstrom \& Dunn, 2014). Regular interactions, both casual and more intentional, contribute to feelings of school connectedness.

While the effect size was small, in a study by Allen, Robbins, Casillas, and Oh (2008) the impact of first-year academic performance and social connectedness demonstrated a significant direct effect on the rate of maintaining enrollment in university in third year. Higher levels of social connectedness are also related to lower levels of loneliness and adjustment difficulties (Duru, 2008) and are correlated with emotional learning and achievement motivation (Turki, Jdaitawi, \& Sheta, 2017). While males and females in university did not differ in their perceived levels of social connectedness, they differed in the qualities they needed to feel socially connected, with females desiring physical proximity and males desiring social comparison or guidance (Lee \& Robbins, 2000).

\section{Self-Efficacy}

Bandura (1977) defined self-efficacy as the combination of believing that an action will have a specific result and believing that one is able perform that action. These two beliefs together impact student behaviour, including effectively implementing strategies, which, in turn, positively influences academic performance (Pajares, 2002). For example, students who believe that completing readings before class will improve their performance and who believe they are able to complete the readings before class are more likely to proactively set aside time to read and, consequently, to complete the readings before class. Students who think that completing the readings is not an effective strategy are not likely to read the assignments. Additionally, students who think that they are unable to complete the readings before class, even if they think that completing the reading assignments ahead of time would be an effective strategy, are unlikely to actually read the assignments.

Relatedly, students with high self-efficacy tend to frame work demands as challenges rather than threats, which results in higher expectations for their performance as well as higher actual academic performance (Chemers, Hu, \& Garcia, 2001). Easy success does not lead to a strong sense of self-efficacy because it does not foster the fortitude necessary to work through challenges. The belief that one can perform an action to bring about a specific result is gained through a cyclical process of persevering through challenging tasks and successfully completing them. Repeatedly surmounting obstacles convinces 
people that they are capable, increasing their self-efficacy and their persistence in tackling challenging problems (Bandura, 1997). Not surprisingly, then, high levels of self-efficacy promote the development of academic motivation and success.

Academic self-efficacy. Academic self-efficacy-belief in one's ability to complete the regulatory tasks needed to succeed academically (Zimmerman, Bandura, \& MartinezPons, 1992)-predicts academic achievement, effort, perseverance, and decreased procrastination in high school and university (Di Giunta et al., 2013; Feldman, Davidson, Ben-Naim, Maza, \& Margalit, 2016; Komarraju \& Nadler, 2013). Interestingly, students who have low expectations for their academic performance tend to adopt an avoidance approach, attempting to not look bad, and as a result often do not seek help (Hsieh, Sullivan, \& Guerr, 2007). There are gender differences in self-efficacy, with females reporting higher levels of confidence in their use of study and organizational strategies and effort maintenance (Pajares, 2002); however, adolescent males report small, but statistically significant, higher levels of academic self-efficacy related to most specific content areas compared to females (Huang, 2013).

High levels of academic self-efficacy positively impact goal-directed, self-regulatory behaviours; they also positively influence grades both directly and indirectly through setting higher goals for academic achievement (Pajares, 2002; Poole \& Evans, 1989). Setting smaller, proximal goals on the path to a larger distal goal is particularly helpful in assisting students to see progress and increase their confidence. Receiving frequent feedback, especially when students are encouraged to connect their performance with effort, results in greater self-efficacy and skill development (Pajares, 2002). In a review of the influence of academic self-efficacy on academic performance, Honicke and Broadbent (2016) found that academic self-efficacy was moderately correlated with academic performance. Richardson, Abraham, and Bond (2012) found that academic self-efficacy was moderately correlated with university grade point average (GPA). One Canadian study identified a positive correlation between students' academic aspirations and actual academic performance and between time spent studying and academic achievement in university (Chow, 2007), suggesting that setting high goals is related to engaging in goal-directed behaviours toward those goals and ultimately to achieving high goals.

Academic competence. Academic competence typically requires engaging in specific activities related with success, including spending time reading and completing coursework. However, over half of high school students report that they spend three hours per week at most on coursework but that this is sufficient for them to competently complete their assigned tasks (McCarthy \& Kuh, 2006; Vinson et al., 2010). These study habits do not adequately prepare students for the demands of university. Competence requires more than simply having skills and knowledge; it also requires executive functioning in order to effectively organize, choose, and perform behaviours that are likely to be successful (Bandura \& Schunk, 1981). Through this process of mastering skills, people develop intrinsic motivation for tasks that initially were not intrinsically motivating for them. Bandura and Schunk (1981) found that when elementary school children set attainable sub-goals in learning math concepts, they improved math skills, perceived selfefficacy, accuracy in assessing their skill, and interest in math, which was originally not intrinsically interesting to them. Additionally, all students who were persistent, whether or not they set attainable sub-goals, were more likely to succeed. 


\section{Academic Satisfaction}

Academic satisfaction or satisfaction with academic studies is somewhat analogous to job satisfaction, and definitions sometimes prioritize cognitive, affective, or attitudinal dimensions (Wach, Karbach, Ruffing, Brünken, \& Spinath, 2016). Students in a teacher education program were more satisfied with the content of their program when they reported high levels of intrinsic motivation and were more satisfied with the conditions of their program when they assumed that the courses would not be difficult (Wach et al., 2016). Further, students who were achieving academically were more satisfied with their program (Wach et al., 2016), suggesting a link between academic competence and academic satisfaction.

\section{Students' Gratitude}

Gratitude is both a state, a temporary feeling or behaviour, and a trait, a stable characteristic (McCullough, Emmons, \& Tsang, 2002). Gratitude is the positive emotional response experienced in relation to receiving a benefit from an external source (Renshaw \& Bolognino, 2016). While there has been limited research examining college gratitude (This is a US scale, which uses university and college interchangeably.), overall gratitude is positively correlated with academic and social integration, GPA, life satisfaction, and positive emotion, and negatively correlated with levels of depression and anxiety, and the number of self-reported course withdrawals and failures (Emmons \& McCullough, 2003; Mofidi, El-Alayi, \& Brown, 2014).

\section{Conscientiousness}

McCrae's and Costa's (1987) Big Five model of personality includes the traits of extraversion, agreeableness, conscientiousness, emotional stability, and openness; of these, conscientiousness and openness are most closely related to strong academic performance (Credé \& Kuncel, 2008; Poropat, 2009). Individuals with high levels of conscientiousness tend to demonstrate specific characteristics such as planning and organization, self-regulation needed to avoid procrastination, sustained effort, persistence, and methodic analytical thinking (Di Giunta et al., 2013); consequently, conscientiousness was negatively correlated and procrastination, and it was positively correlated with GPA (Richardson et al., 2012). It is not surprising, then, that conscientiousness, in conjunction with openness and self-esteem, contributed to academic self-efficacy in high school students (Di Giunta et al., 2013). Additionally, despite the popular view that characterizes individuals who are conscientious as being rigid, especially in their impulse control, the aspect of executive functioning most closely associated with conscientiousness was cognitive flexibility, or the capacity to adapt effectively to changing demands (Fleming, Heintzelman, \& Bartholow, 2016).

\section{Mental Health}

Findings from studies indicate a high prevalence of distress and mental health symptoms among university students. One Australian study found that undergraduate students reported significantly higher rates of distress (83.9\%) than the general population (29\%), with females reporting higher levels of distress than males (Stallman, 2010). In 
another study, $13.8 \%$ of undergraduate respondents has positive screens for depression and $2.9 \%$ for anxiety, and while rates of positive depression screens were similar for males and females, females were more than twice as likely to screen positively for an anxiety disorder (Eisenberg, Gollust, Golberstein, \& Hefner, 2007). Of the students who screened positively for one disorder, almost one-quarter screened positively for a second condition (Eisenberg, et al., 2007). A U.S. study found that more than one-third of students reported a mental health problem (anxiety: 4 to $7 \%$; depression 13 to $15 \%$ ) and $60 \%$ of those students reported a mental health problem two years later, but many of these students did not think that they needed to pursue help (Zavin, Eisenberg, Gollust, \& Golbertein, 2009). Additionally, students who reported increased mental health problems achieved lower GPAs (Stallman, 2010). In a longitudinal study examining the impact of mental health problems on achievement, Eisenberg, Golberstein, and Hunt (2009) found that depression alone predicted low GPA, and that the combination of depression and anxiety was a particularly strong predictor of poor achievement.

\section{Current Study}

1. The main purposes of the current study are as follows: to investigate whether university student well-being predicts student life satisfaction and academic achievement; to investigate whether the personality factor conscientiousness, together with life satisfaction, predict academic self-efficacy; to determine whether university student well-being predicts academic achievement in transitioning undergraduate students; and to determine whether anxiety and depression predict achievement in transitioning university students. In addition, an analysis of gender will be conducted on the variables used in the current study to determine whether there are any domain-specific differences prior to entering variable into the main regression analyses. There were five research questions for the current study: Are there gender differences in the variables measured in the current study?

2. Does university student well-being, as measured by academic satisfaction, academic self-efficacy, school connectedness, and college gratitude, predict satisfaction with life in transitioning undergraduate students?

3. Does the personality factor conscientiousness and life satisfaction predict academic self-efficacy in transitioning undergraduate students?

4. Does university student well-being predict achievement in transitioning university students?

5. Do anxiety and depression predict achievement in transitioning university students?

Method

\section{Participants}

The sample for the current study consisted of 71 participants (19 male, 52 female). This sample was taken from the population of first-year transitioning students. Mean age was 19.04 years with a standard deviation of 1.75 years (range: 18-25 years old). Participants were recruited from undergraduate programs across various university faculties: science (31.8\%), arts (30.3\%), business (15.2\%), medicine (9.1\%), education (3\%), kinesiology (3\%), and nursing (3\%), and the remainder had not declared a major (4.6\%). 


\section{Instrumentation}

Academic achievement. Students reported their first semester grades as a percentage.

College Student Subjective Well-being Questionnaire (CSSWQ). Subjective well-being was measured using CSSWQ, a 16-item self-report behaviour rating scale for measuring undergraduate students' college-specific wellbeing. It is comprised of four subscales with four items per subscale, measuring the following: (1) Academic Satisfaction (e.g., I am happy with how I have done in my classes.), (2) Academic Efficacy (e.g., I am an organized and effective student.), (3) School Connectedness (e.g., People at this school are friendly to me.), and (4) College Gratitude (e.g., I feel thankful for the opportunity to learn so many new things.). Responses are recorded on a Likert-type scale ranging from 1 (strongly disagree) to 7 (strongly agree). Item responses are summed to create subscale scores, and subscales can be combined to create a total score. Research shows that each of the subscales of the CSSWQ and the total score possess adequate internal consistency reliability. The coefficient alphas for each subscale and the total score are as follows: Academic Satisfaction, $\alpha=.88$; Academic Efficacy, $\alpha=.86$; School Connectedness, $\alpha=.83$; College Gratitude, $\alpha=.79$; and total score, $\alpha=.91$ (Renshaw, 2018).

Satisfaction with Life Scale (SWLS). Satisfaction with life was measured using the SWLS, which consists of five items examining respondents' global judgement of life satisfaction, which is thought to converge highly with emotional well-being. The items are comprised of statements such as "In most ways my life is close to ideal." Responses are recorded on a Likert-type scale ranging from 1 (strongly disagree) to 7 (strongly agree). Item responses are summed to create a total score. Higher scores indicate greater satisfaction with life. Test-retest reliability has been reported to be strong ( $\alpha=.87$; Diener, Emmons, Larsen, \& Griffin, 1985). Considerable evidence for the construct validity of the SWLS has been reported (e.g., Diener et al., 1985; Pavot, Diener, Colvith, \& Sandvik, 1991; Pavot \& Diener, 1993).

Mini-markers. Participant personality was measured using Saucier's (1994) Minimarkers. This is a 44-item self-report scale used to assess dimensions of personality according to McCrae's and Costa's (1987) Big Five personality model. The measure provides scores for extraversion (e.g., Bold), conscientiousness (e.g., Organized), intellectualism (e.g., Creative), agreeableness (e.g., Cooperative), and emotional stability (e.g., Relaxed). Participants rated how much each personality adjective described them using a 9-point Likert scale. The score for each participant is determined by taking the mean of the rating for each item under each factor. The scale has a five-factor solution, with each factor having an internal consistency of $\alpha=.78$ to $\alpha=.87$. These adjectives were selected from Goldberg's (1992) 100-item measure and were selected based on factor purity. Because the items were selected from a previously and more widely used measure of personality due to their robustness, the Mini-markers have demonstrated concurrent validity. Additionally, the scale has demonstrated convergent and divergent validity similar to Goldberg's (1992) measure, with comparable correlations between personality facets and academic achievement (Dwight, Cummings, \& Glenar, 1998), as well as gender, age, life satisfaction, and emotional intelligence (Palmer \& Loveland, 2004). 
Depression Anxiety Stress Scale (DASS-21). Depression and anxiety were measured using the DASS-21, a 21-item scale that provides brief measures of depression, anxiety, and stress (Lovibond \& Lovibond, 1995). There are seven items for each of the subscales. The items are comprised of statements such as "I find it hard to wind down." Responses are recorded on a 4-point Likert-type scale ranging from o (did not apply to me at all) to 3 (applied to me very much, or most of the time). Research supports the reliability and validity of the DASS-21 with coefficient alphas of $\alpha=.85$ for the depression subscale, $\alpha$ $=.81$ for the anxiety subscale, and $\alpha=.88$ for the stress subscale (Osman et al., 2012). The DASS-21 anxiety and depression subscales possess significant positive correlations with the Beck anxiety and depression inventories respectively (Osman et al., 2012).

\section{Procedure}

Following approval from the Conjoint Faculties Research Ethics Board (CFREB) at the University of Calgary, the researchers contacted undergraduate instructors from all faculties to seek permission for classroom recruitment at the beginning of the winter term. After receiving permission, the researchers presented a general invitation to students during regularly scheduled first-year undergraduate lectures. The researchers provided interested students with a link where participants provided self-report data using an online survey system (FluidSurveys). When participants visited the survey website, they were provided with the appropriate consent documentation and asked to indicate that they consented to participating in the study. Once into the survey, participants were asked to provide their demographic information, previous high school achievement, and first-term achievement, and to complete all of the scales. The estimated time to complete the survey was approximately 20 minutes.

\section{Data Analysis}

All data analyses were conducted using SPSS 24.o. The first part of the data analysis involved checking the integrity of the data (i.e., outliers and missing data as well as testing the assumptions of the statistical tests for the analysis). This involved visually inspecting histograms and boxplots, as well as skew and kurtosis values for each of the variables that were to be entered into the regression analysis. To determine whether there were gender differences on the variables utilized in the current study, a series of $t$-tests were conducted utilizing a Bonferroni correction to adjust the nominal alpha in order to protect against familywise error. Gender analysis was conducted prior to the regression analysis to ensure that there were no differences, as subgroups with differing intercepts and/or slopes can bias the result of a regression analysis. To answer the main research questions, scale scores were entered into a series of linear regressions. Linear regression implied directionality in the relationship between one or more predictor variable and an outcome variable (Kerlinger \& Lee, 2000). The first two regression analyses were conducted utilizing the entire data set; however, due to missing data on the achievement (GPA) variable, the third and fourth regression analyses were conducted on a reduced sample. 


\section{Results}

\section{Data Inspection}

Visual inspection of the data revealed that there were five cases with $100 \%$ missing data. These cases were dealt with by utilizing listwise deletion, resulting in 66 participants (Tabachnick \& Fidell, 2012). Once these cases were removed, there was less than $3 \%$ missing data for any single variable. This was also the case for each participant, where there was also less than $3 \%$ missing data. Multiple imputation was utilized to deal with the remaining missing data. Visual inspection of boxplots revealed that there were no outliers present in the data. Histograms and skew and kurtosis values were checked to assess whether the assumption of normality was satisfied and all variables demonstrated acceptable levels of skew and kurtosis, thus satisfying the assumption of normality (Tabachnick \& Fidell, 2012). In addition, of the 66 remaining participants, there was $59.1 \%$ missing data for first semester grades, meaning that only 27 participants provided information pertaining to their achievement. Since academic achievement was an important outcome variable for the current study, a decision was made to conduct a separate set of regression analyses on these participants using this smaller sample. Participant data where achievement information was provided was copied to a secondary data set. The number of participants utilized in each regression analysis are indicated in the results of the regression analyses.

\section{Descriptive Statistics}

Means, standard deviations, minimum value, maximum value, and skew and kurtosis values for each of the measures used in the current study are listed in Table 1. Bivariate correlations between all of the variables measured in the current study are listed in Table 2.

\section{Gender Analysis}

To address research question one, an analysis of gender differences was conducted on the variables used in the current study. All participants in the study indicated that they identified their gender as male or female. Results from the series of $t$-tests utilizing Bonferroni corrections indicated that there were no gender differences for any of the variables measured in the study.

\section{Regression Analysis}

The main analysis of the current study consisted of four linear regression analyses to answer questions two through five. Across all regression analyses conducted, inspection of the Durbin-Watson value, tolerance values, and residual plot indicates that there was no evidence of violations of the assumptions related to regression. The first linear regression $(n=66)$ utilized the four subscales from the CSSWQ (i.e., academic satisfaction, academic self-efficacy, school connectedness scales, and college gratitude), with satisfaction with life as the outcome variable. This resulted in a model where these variables accounted for $49 \%$ of the variability in the participants' satisfaction with life, $R^{2}{ }_{\text {adj }}=.485$, $F(4,61)=16.32, p<.001$. The standardized coefficients for academic satisfaction and school connectedness were $\beta=.32, p=.005$ and $\beta=.45, p=.001$, respectively. Academic self-efficacy $(\beta=.10, p=.39)$ and college gratitude $(\beta=.06, p=.53)$ were not significant predictors in this model. 
Table 1. Descriptive statistics

\begin{tabular}{lcccccc}
\hline & Mean & $\begin{array}{c}\text { Standard } \\
\text { Deviation }\end{array}$ & Minimum & Maximum & Skew & Kurtosis \\
\hline CSSWQ: Total Score & 18.68 & 5.44 & 5.00 & 28.00 & -0.37 & -0.57 \\
CSSWQ: Academic Satisfaction & 21.97 & 3.78 & 11.00 & 28.00 & -0.67 & 0.13 \\
CSSWQ: Academic Efficacy & 21.12 & 3.63 & 14.00 & 28.00 & -0.03 & -0.90 \\
CSSWQ: School Connectedness & 24.60 & 3.40 & 15.00 & 39.06 & 0.52 & 4.57 \\
CSSWQ: College Gratitude & 86.37 & 12.50 & 54.00 & 112.00 & -0.22 & -0.40 \\
Mini-Markers: Extraversion & 41.91 & 10.74 & 13.00 & 64.00 & -0.26 & 0.38 \\
Mini-Markers: Agreeableness & 54.07 & 9.87 & 31.00 & 69.00 & -0.33 & -0.84 \\
Mini-Markers: & 50.90 & 10.53 & 19.00 & 71.00 & -0.89 & 1.02 \\
$\quad$ Conscientiousness & & & & & & \\
Mini-Markers: Emotional & 39.73 & 11.39 & 9.00 & 69.00 & 0.10 & 0.41 \\
$\quad$ Stability & 50.98 & 10.04 & 30.00 & 71.00 & 0.01 & -0.71 \\
Mini-Markers: Openness & 22.74 & 7.42 & 5.00 & 35.00 & -0.47 & -0.45 \\
Satisfaction with Life & & & & & & \\
\hline
\end{tabular}

The second linear regression $(n=66)$ utilized the personality factor conscientiousness with academic self-efficacy as the outcome variable. This resulted in a model where conscientiousness accounted for $42 \%$ of the variability of the participants' academic selfefficacy, $R^{2}{ }_{\text {adj }}=.421, F(1,64)=41.16, p<.001$. The standardized coefficients for conscientiousness were $\beta=.63, p<.001$.

The third linear regression $(n=27)$ utilized the CSSWQ total score as the predictor and academic achievement as the outcome. The total CSSWQ score was used instead of subscale scores in this regression analysis due to the small sample size, resulting in a limited ability to mine down into subscale scores due to reduction in power and the limited number of factors that could be entered into the regression. The purpose of this analysis was to determine if global college student well-being was related to achievement. This resulted in a model accounting for $48 \%$ of the variability of the participants' academic achievement, $R^{2}{ }_{\text {adj }}=.484, F(1,25)=7.66, p=.01$. The standardized coefficient for the CSSWQ was, $\beta=.484, p=.01$.

The fourth linear regression $(n=27)$ used the DASS-21 anxiety and depression subscale scores as the predictors, with academic achievement as the outcome. Stress was not entered into the model due to high collinearity with anxiety and depression. The purpose of this analysis was to determine if aspects of mental health were related to academic achievement. This resulted in a model accounting for $32 \%$ of the variability in academic achievement, $R_{\text {adj }}=.32, F(2,24)=7.08, p=.004$. The standardized coefficients for anxiety and depression were $\beta=-.55, p=.004$ and $\beta=-.114, p>.05$, respectively. Depression was not a significant predictor in the model. 


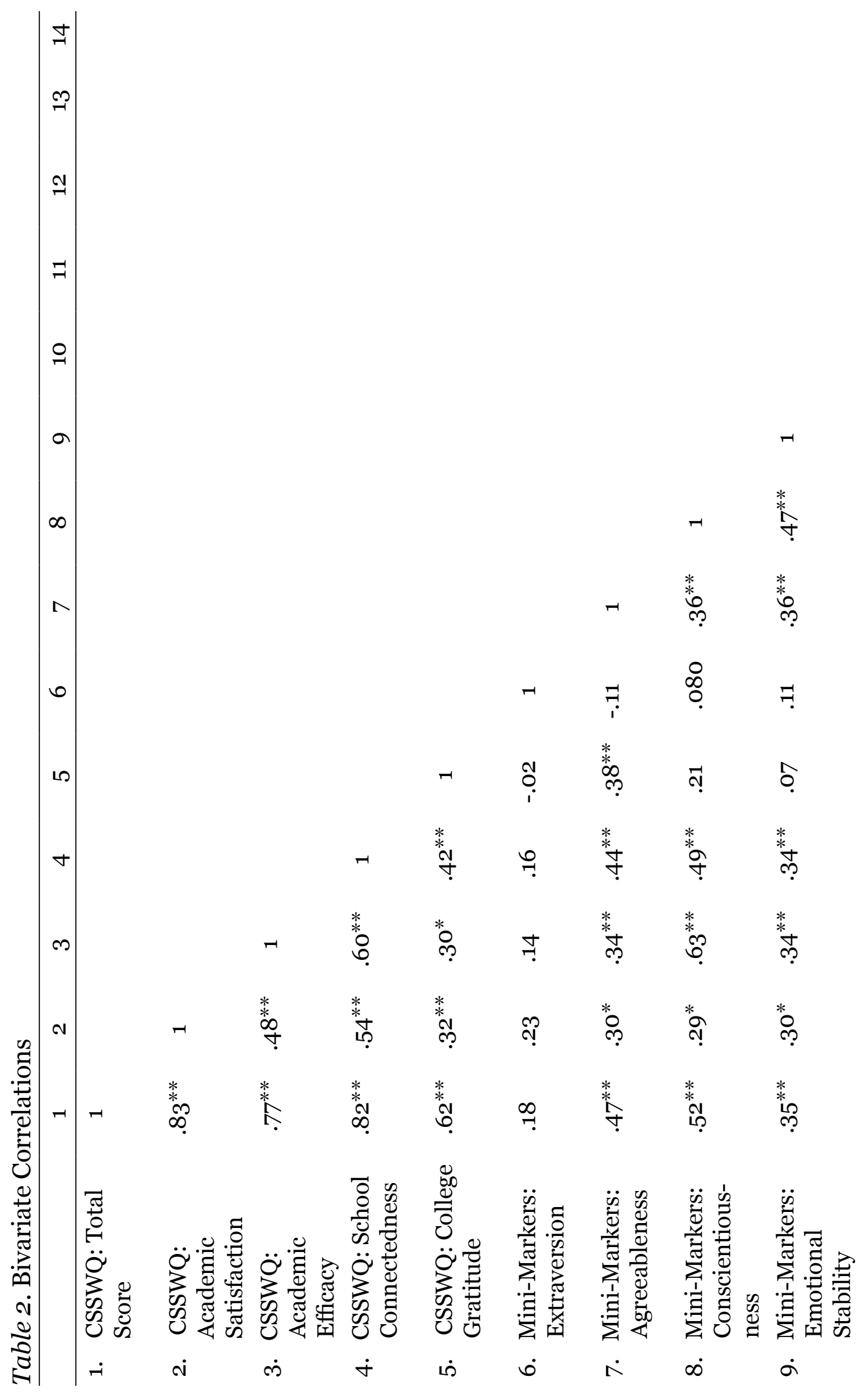




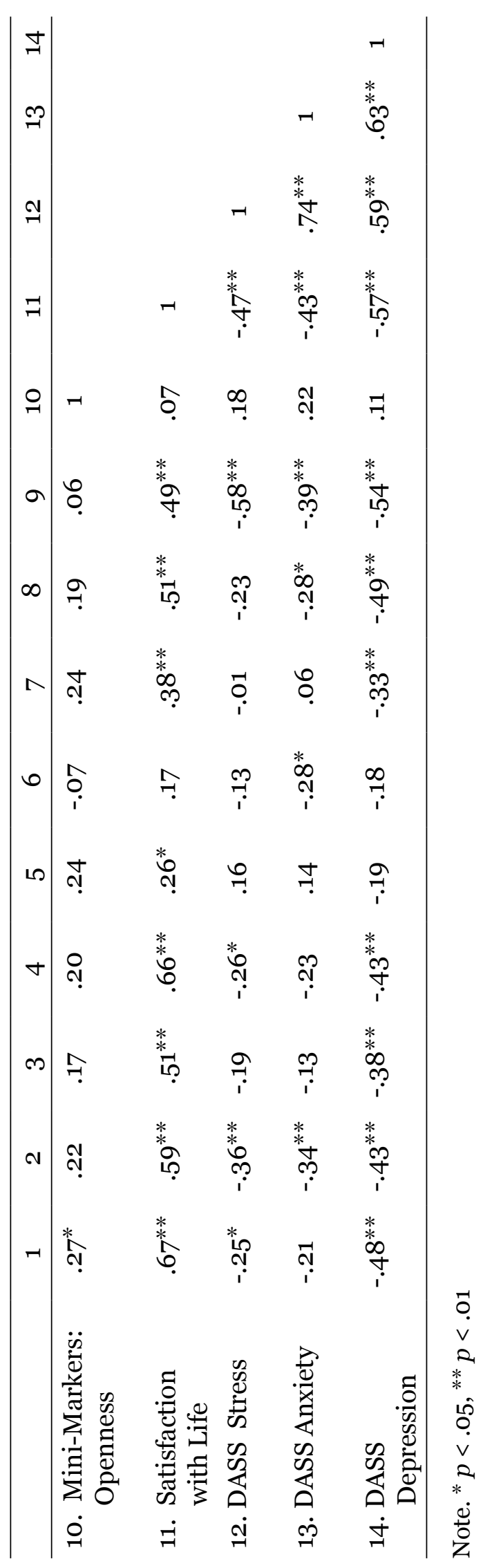




\section{Discussion}

In this study, we asked five questions related to students who are transitioning to university. In the first, we found that there were no difference between males and females on any variable measured in this study. Other studies found variable gender differences on similar measures. For example, Turki, Jdaitawi, and Sheta (2017) found no differences in social connectedness or achievement motivation, but they found that males demonstrated higher levels of social emotional learning. Another study (Eisenberg et al., 2007) found that females reported higher levels of distress, related to mental health, than males. Our finding could be due to the characteristics of the students who chose to participate and the measures we used.

In answering the second question, we found that academic satisfaction and school connectedness accounted for $49 \%$ of the variance in satisfaction with life, and that academic self-efficacy and college gratitude were not significant predictors of satisfaction with life. In the current study, the academic satisfaction subscale of the CSSWQ reflected students' perception of their academic performance at university and its importance to their overall satisfaction with life. This finding is in line with other research on academic satisfaction and satisfaction with life (Wach et al., 2016) and with research examining the role of school connectedness with adjustment (Duru, 2008), well-being (Sandstrom \& Dunn, 2014), depression (Armstrong \& Oomen-Early, 2009), and retention (Allen et al., 2008). Turki and colleagues (2017), however, found that social connectedness was correlated with social and emotional learning but not with adjustment. While our measure of the impact of school connectedness on well-being was somewhat different from the focus of other studies, the results of most other studies examining comparable constructs were similar to our results. In the current study, academic self-efficacy was not a significant predictor of satisfaction with life, which is surprising given the amount of research that has demonstrated this relationship (Chemers et al., 2001; Di Giunta et al., 2013; Honicke \& Broadbent, 2016; Komarraju \& Nadler, 2013; Richardson et al., 2012. The non-significant finding in the current study could be due to the measure that was used. The nonsignificant find pertaining to college gratitude was also somewhat surprising; however, there is not a great deal of research focusing on this construct.

Conscientiousness accounts of $42 \%$ of the variance in academic self-efficacy in answer to the third question. This finding is in line with other research indicating that students who are organized, precise, and persistent in their approach to work are more likely to believe that they have the skills necessary to complete difficult aspects of coursework, which is an integral component of self-efficacy (Bandura \& Schunk, 1981; Di Giunta et al., 2013). While not in a university population, Di Giunta and colleagues found that conscientiousness contributed to academic self-efficacy as well, suggesting that personality, specifically conscientiousness, is an important factor contributing to successful academic transition to university.

In answering the fourth research question, we found that college well-being accounted for $43 \%$ of the variance in self-reported achievement. The measure of college well-being was broad and included academic satisfaction, academic self-efficacy, school connectedness, and college gratitude. Our findings are supported by other studies suggesting that higher life satisfaction (Rode et al., 2005) and higher well-being (Chow, 2007) are corre- 
lated with higher GPA. In answering the final research question, we found that anxiety accounted for $32 \%$ of the variance in achievement and that depression was not a significant predictor of achievement. This finding is in line with other research finding that increased mental health problems are related to decreases in academic achievement, specifically in GPA (Eisenberg et al., 2007; Stallman, 20010. The finding that depression was not a predictor of achievement was surprising, however, because Eisenberg and colleagues (2009) found that depression alone significantly predicted lower GPA, and that a combination of depression and anxiety was a strong predictor of poor achievement.

\section{Implications}

There are multiple practice implications from this study. Students would likely benefit from increased preparation for university both through their high school experiences and during the transition. While we did not measure specific study skills, some of the questions on the conscientiousness subscale asked questions in this vein (e.g., if students were organized, efficient, etc.). Research suggests that current high school expectations do not prepare students for the work demands of university, as they can achieve satisfactorily with three or fewer hours per week spent on coursework in high school (Bandura, 1997; McCarthy \& Kuh, 2006; Vinson et al. 2010). Additionally, students who reported taking challenging course loads in high school also reported that they felt that those challenging classes prepared them to complete the work required at university (Nordstokke \& Wilcox, 2018).

After students have entered university, they may benefit from programs to support social connection, effective learning strategies for the differing demands of university, and mental health-both fostering mental health and providing help for those who experience mental health symptoms, especially in the areas of depression and anxiety. Fostering a university culture of safe help-seeking could expand beyond mental health to academic support. This could be aided by helping students identify their academic and study skill strengths and weaknesses and creating easy paths to seeking help embedded within courses rather than expecting students to seek out the supports, as students who need supports often do not seek them out (Feldman et al., 2016; Vinson et al., 2010).

Unfortunately, students who report high levels of distress and symptoms of mental health diagnoses do not always acknowledge that they need help or seek out supports, even when those exist. By encouraging help-seeking behaviours (Zavin et al., 2009), universities can help to address this. For example, they can examine barriers to accessing services offered, such as lack of information, stigma, and logistical difficulties in accessing services (e.g., location, hours, scheduling) to determine university-specific strategies for reducing those barriers. Preventatively, programs that promote positive engagement, not only with peers but also with faculty, are important in successful transition support programs (Vinson et al., 2010).

\section{Limitations}

There are several limitations to the current study that should be addressed. It should be noted that these limitations do not invalidate the results of the current study but should be addressed to strengthen future work. The first limitation relates to the measures that were utilized. The CSSWQ was selected because it is a multidimensional measure of col- 
lege student well-being (Renshaw, 2018); however, a potential issue with such a broad measure is that it may not adequately represent the subscale constructs (e.g., academic self-efficacy), possibly explaining some of the null results reported in this study. Additionally, this was the only global scale of college student subjective well-being available. To address this in future studies, we will either employ other measurement scales, if available or develop measurement instruments. The DASS-21 provides only a snapshot of the mental health status of students (Lovibond \& Lovibond, 1995), and therefore does not fully reflect the extent to which students are experiencing mental health challenges. A particular point to note is that the anxiety component of the DASS-21 only explores somatic aspects of anxiety and does not address the importance of other aspects of anxiety (i.e., rumination and cognitive symptoms). To address this in future studies, more comprehensive mental health assessments will help to determine more completely the relationships between student mental health, transition, and achievement.

A second limitation of the current study is related to challenges in recruitment and student responses. Several attempts to recruit transitioning students were made, but overall there was low participation in the study. In addition, many more females than males participated in the current study. This may have resulted in an imbalanced representation of female/male experiences. However, since there were no gender differences on the variables utilized in the current study, this is not likely. A final challenge faced in the current study pertained to student reporting of their grades. There was over $50 \%$ missing data on this variable; to address this in future research, partnerships will be developed with the university registrar to ensure access to more complete data.

\section{Future Research}

How best to support students as they transition into university is an area requiring additional research. One area to address in future research is the experiences and outcomes of specific at-risk populations. University has become more accessible to individuals with high-incidence disabilities, including mental health diagnoses, learning disabilities, attention deficit hyperactivity disorder (ADHD), and high-functioning autism. However, gaining admission to university is not enough; these students have unique needs that require supports in order for them to successfully complete university, and there is a need to further determine how best to do that (Moriña, Cortés-Vega, \& Molina, 2015). There are also students who enter university who do not have an official diagnosis but are at risk of an unsuccessful transition due to undiagnosed or undisclosed diagnoses or subthreshold symptoms. Research to help identify these students early in their university experience will help to develop appropriate supports that will increase their likelihood of successfully completing their degree. Increased internationalization has resulted in students attending universities in North America whose first language is not English, and for whom Western culture is foreign. It is also important to continue to research the factors that support successful completion of university in the areas of both academic success and well-being for these unique populations.

\section{Conclusions}

This study found that satisfaction with life was predicted by academic satisfaction and school connectedness, academic self-efficacy was predicted by conscientiousness, and 
self-reported academic achievement was predicted by both college well-being and anxiety. These findings suggest that it is important to support student mental health during the first year of university. They also indicate that aspects of conscientiousness might be important points of focus in terms of developing skill-building programming, as this personality factor seems to be a multifaceted construct and some aspects appear to be skillbased. This would suggest that programming could be developed to address these issues for some students. Finally, academic satisfaction and school connectedness are important factors related to student satisfaction with life, and universities should explore ways of engaging first-year students in terms of fostering their connectedness to the institution and supporting students to promote their academic satisfaction.

\section{References}

Allen, J., Robbins, S. B., Casillas, A. \& Oh, I.-S. (2008). Third-year college retention and transfer: Effects of academic performance, motivation, and social connectedness. Research in Higher Education, 49(7), 647-664. https://doi.org/10.1007/s11162-0089098-3

Armstrong, S., \& Oomen-Early, J. (2009). Social connectedness, self-esteem, and depression symptomatology among collegiate athletes versus nonathletes. Journal of American College Health, 57(5), 521-526. https://doi.org/10.3200/JACH.57.5.521-526

Bandura, A. (1977). Self-efficacy: Toward a unifying theory of behavioral change. Psychological Review, 84(2), 191-215.

Bandura, A. (1997). Self-efficacy: The exercise of control. New York, NY: W. H. Freeman and Company.

Bandura, A., \& Schunk, D. H. (1981). Cultivating competence, self-efficacy, and intrinsic interest through proximal self-motivation. Journal of Personality and Social Psychology, 41(3), 586-598.

Blair, A. (2017). Understanding first-year students' transition to university: A pilot study with implications for student engagement, assessment, and feedback. Learning and Teaching in Politics and International Studies, 37(2), 215-228. https://doi. org/10.1177/0263395716633904

Burke, T., Ruppel, E., \& Dinsmore, D. (2016) Moving away and reaching out: Young adults' relational maintenance and psychosocial well-being during the transition to college. Journal of Family Communication, 16(2), 180-187. https://doi/10.1080/152674 31.2016.1146724

Chemers, M. M., Hu, L., \& Garcia, B. F. (2001). Academic self-efficacy and first year student performance and adjustment. Journal of Educational Psychology, 93(1), 55-64. https://doi.org/10.1037/0022-0663.93.1.55

Chow, H. P. H. (2007). Psychological well-being and scholastic achievement among university students in a Canadian prairie city. Social Psychology in Education, 10(4), 483-493. https://doi.org/10.1007/s11218-007-9026-y

Credé, M., \& Kuncel, N. R. (2008). Study habits, skills, and attitudes: The third pillar supporting collegiate academic performance. Perspectives on Psychological Science, 3(6), 425-453. https://doi.org/10.1111/j.1745-6924.2008.00089.x 
Credé, M., \& Niehorster, S. (2012). Adjustment to college as measured by the student adaptation to college questionnaire: A quantitative review of its structure and relationships with correlates and consequences. Educational Psychology Review, 24(1), 133-165. https://doi.org/10.1007/s10648-011-9184-5

Diener, E., Emmons, R. A., Larsen, R. J., \& Griffin, S. (1985). The Satisfaction with Life Scale. Journal of Personality Assessment, 49, 71-75.

Diener, E., Lucas, R. E., \& Oishi, S. (2005). Subjective well-being: The science of happiness and life satisfaction. In C. R. Snyder \& S. J. Lopez (Eds.), Handbook of positive psychology (pp. 63-73). New York, NY: Oxford.

Di Giunta, L., Alessandri, G., Gerbino, M., Kancri, P. M., Zuffiano, A., \& Capra, C. G. (2013). The determinants of scholastic achievement: The contribution of personality traits, self-esteem, and academic self-efficacy. Learning and Individual Differences, 27, 102-108. https://doi.org/10.1016/j.lindif.2013.07.006

Duru, E. (2008). The predictive analysis of adjustment difficulties from loneliness, social support, and social connectedness. Educational Sciences: Theory \& Practice, 8(3), $849-856$.

Dwight, S. A., Cummings, K. M., \& Glenar, J. L. (1998). Comparison of criterionrelated validity coefficients for the mini-markers and Goldberg's markers of the big five personality factors. Journal of Personality Assessment, 7O(3), 541-550.

Eisenberg, D., Golberstein, E., \& Hunt, J. B. (2009). Mental health and academic success in college. The BE Journal of Economic Analysis \& Policy, 9, 1-35. https://doi. org/10.2202/1935-1682.2191

Eisenberg, D., Gollust, S. E., Golberstein, E., \& Hefner, J. L. (2007). Prevalence and correlates of depression, anxiety, and suicidality among university students. American Journal of Orthopsychiatry, 77(4), 534-542. https://doi.org/10.1037/00029432.77.4.534

Emmons, R. A., \& McCullough, M. E. (2003). Counting blessings versus burdens: An experimental investigation of gratitude and subjective well-being in daily life. Journal of Personality and Social Psychology, 84(2), 377-389. https://doi.org/10.1037/00223514.84.2.377

Feldman, D. B., Davidson, O. B., Ben-Naim, S., Maza, E., \& Margalit, M. (2016). Hope as a mediator of loneliness and academic self-efficacy among students with and without learning disabilities during transition to college. Learning Disabilities Research \& Practice, 31(2), 63-74. https://doi.org/10.1111/ldrp.12094

Fleming, K. A., Heintzelman, S. J., \& Bartholow, B. D. (2016). Specifying associations between conscientiousness and executive functioning: Mental set shifting, not prepotent response inhibition or working memory updating. Journal of Personality, 84(3), 34836o. https://doi.org/10.1111/jopy.12163

Fromme, K., Corbin, W. R., \& Kruse, M. I. (2008). Behavioral risks during the transition from high school to college. Developmental Psychology, 44(5), 1497-1504. https://doi. org/10.1037/aoo12614 
Goldberg, L. R. (1992). The development of markers for the Big-Five factor structure. Psychological Assessment, 4(1), 26-42.

Honicke, T., \& Broadbent, J. (2016). The influence of academic self-efficacy on academic performance: A systematic review. Educational Research Review, 17, 63-84. https://doi.org/10.1016/j.edurev.2015.11.002

Hsieh, P., Sullivan, J. R., \& Guerr, N. S. (2007). A closer look at college students: Selfefficacy and goal orientation. Journal of Advanced Academics, 18(3), 454-476. https:// doi.org/10.4219/jaa-2007-500

Huang, C. (2013). Gender differences in academic self-efficacy: A meta-analysis. European Journal of Educational Psychology, 28(1), 1-35. https://doi.org/10.1007/ s10212-011-0097-y

Knapp, L. G. (2007). Enrollment in postsecondary institutions, Fall 2005 graduation rates, 1999 and 2002 cohorts and financial statistics, fiscal year 2005. First look. NCES Document No. 2007-154. Washington, DC: National Center for Educational Statistics.

Kerlinger, F. \& Lee, H. (2000). Foundations of behavioral research (4th ed.) Belmont, CA: Wadsworth.

Komarraju, M., \& Nadler, D, (2013). Self-efficacy and academic achievement: Why do implicit beliefs, goals, and effort regulation matter? Learning and Individual Differences, 25, 67-72. https://doi.org/10.1016/j.lindif.2013.01.005

Lee, R. M., \& Robbins, S. B. (1995). Measuring belongingness: The Social Connectedness and Social Assurance Scales. Journal of Counseling Psychology, 42, 232-241.

Lee, R. M., \& Robbins, S. B. (2000). Understanding social connectedness in college women and men. Journal of Counseling \& Development, 78, 484-491. https://doi. org/10.1002/j.1556-6676.2000.tb01932.x

Lovibond, P. F., \& Lovibond, S. H. (1995). The structure of negative emotional states: Comparison of the Depression Anxiety Stress Scale (DASS) with the Beck Depression and Anxiety Inventories. Behaviour Research and Therapy, 33, 335-343.

McCarthy, M., \& Kuh, G. D. (2006). Are students ready for college? What student engagement data say Phi Delta Kappan, 87(9), 664-669. https://doi. org/10.1177/003172170608700909

McCullough, M. E., Emmons, R. A., \& Tsang, J. (2002). The grateful disposition: A conceptual and empirical topography. Journal of Personality and Social Psychology, 82(1), 112-127. https://doi.org/10.1037//o022-3514.82.1.112

McCrae, R. R., \& Costa, P. T. (1987). Validation of the five-factor model of personality across instruments and observers. Journal of Personality and Social Psychology, 52(1), 81-90.

Mofidi, T., El-Alayi, A., \& Brown, A. A. (2014). Trait gratitude and grateful coping as they relate to college student persistence, success, and integration in school. Journal of College Student Retention: Research, Theory, \& Practice, 16(3), 325-349. https://doi. org/10.2190/CS.16.3.b 
Moriña, A., Cortés-Vega, M. D., \& Molina, V. M. (2015). What if we could imaging ideal faculty? Proposals for improvement by university students with disabilities. Teaching and Teacher Education, 52, 91-98. https://doi.org/10.1016/j.tate.2015.09.008

Nordstokke, D., \& Wilcox, G. (2018). Personal factors and supports that influence the transition to university. Manuscript in preparation.

Oishi, S., Diener, E., \& Lucas, R. E. (2007). The optimum level of well-being: Can people be too happy? Perspectives on Psychological Science, 2, 234-36o. https://doi. org/10.1111/j.1745-6916.2007.00048.x

Osman, A., Wong, J. L, Bagge, C. L., Freedenthal, S., Gutierrez, P. M., \& Lozano, G. (2012). The Depression Anxiety Stress Scale-21 (DASS-21): Further examination of dimensions, scale reliability, and correlates. Journal of Clinical Psychology, 68, 13221338. https://doi.org/10.1002/jclp.21908

Pajares, F. (2002). Gender and perceived self-efficacy in self-regulated learning. Theory into Practice, 41(2), 116-125. https://doi.org/10.1207/s15430421tip4102_8

Palmer, J. K., \& Loveland, J. M. (2004). Further investigation of the psychometric properties of Saucier's big five 'Mini-Markers': Evidence for criterion and construct validity. Individual Differences Research, 2(3), 231-238.

Pavot, W., \& Diener, E. (1993). Review of the Satisfaction with Life Scale. Psychological Assessment, 5, 164-172.

Pavot, W., Diener, E., Colvin, C., \& Sandvik, E. (1991). Further validation of the Satisfaction with Life Scale: Evidence for the cross-method convergence of well-being measures. Journal of Personality Assessment, 57(1), 149-161.

Perera, H. N., McIlveen, P., \& Oliver, M. E. (2015). The mediating roles of coping and adjustment in the relationship between personality and academic achievement. British Journal of Educational Psychology, 85, 440-457. https://doi.org/10.1111/bjep.12084

Poole, M. E., \& Evans, G. T. (1989). Adolescents' self-perceptions of competence in life skill areas. Journal of Youth and Adolescence, 18(2), 147-173.

Poropat, A. E. (2009). A meta-analysis of the five-factor model of personality and academic performance. Psychological Bulletin, 135(2), 322-338. https://doi. org/10.1037/aoo14996

Proctor, C. L., Linley, P. A., \& Maltby, J. (2009). Youth life satisfaction: A review of the literature. Journal of Happiness Studies, 1O(5), 583-630. https://doi.org/10.1007/ s10902-008-9110-9

Renshaw, T. L. (2018). Psychometrics of the revised College Student Subjective Wellbeing Questionnaire. Canadian Journal of School Psychology, 33(2), 136-149. https://doi.org/10.1177/0829573516678704

Renshaw, T. L. \& Bolognino, S. J. (2016). The College Student Subjective Wellbeing Questionnaire: A brief, multidimensional measure of undergraduates' covitality. Journal of Happiness Studies, 17(23), 463-484. https://doi.org/10.1007/s10902-014-9606-4 
Richardson, M., Abraham, C., \& Bond, R. (2012). Psychological correlates of university academic performance: A systematic review and meta-analysis. Psychological Bulletin, 138(2), 353-387. https://doi.org/10.1037/a0026838

Rode, J. C., Arthaud-Day, M. L., Mooney, C. H., Near, J. P., Baldwin, T. T., Bommer, W. H., \& Rubin, R. S. (2005). Life satisfaction and student performance. Academy of Management Learning \& Education, 4(4), 421-433. https://doi.org/10.5465/ AMLE.2005.19086784

Sandstrom, G. M., \& Dunn, E. W. (2014). Social interactions and well-being: The surprising power of weak ties. Personality and Social Psychology Bulletin, 4O(7), 910922. https://doi.org/10.1177/0146167214529799

Saucier, G. (1994). Mini-markers: A brief version of Goldberg's unipolar big-five markers. Journal of Personality Assessment, 63(3), 506-516.

Smith, W. L. \& Zhang, P. (2008). Perceived factors facilitating students' transition from high school to college. Michigan Sociological Review, 22(1), 19-40.

Stallman, H. M. (2010). Psychological distress in university students: A comparison with general population data. Australian Psychologist, 45(4), 249-257. https://doi.org/ 10.1080/00050067.2010.482109

Stamp, E., Crust, L., Swann, C., Perry, J., Clough, P., \& Marchant, D. (2015). Relationships between mental toughness and psychological wellbeing in undergraduate students. Personality and Individual Differences, 75, 170-174. https://doi.org/10.1016/j. paid.2014.11.038

Suldo, S. M., Riley, K. N., \& Schaffer, E. J. (2006). Academic correlates of children and adolescents' life satisfaction. School Psychology International, 27, 567-582. https://doi. org/10.1177/0143034306073411

Tabachnick, B., \& Fidell, L. (2012). Using multivariate statistics (6th ed.). Toronto, ON: Pearson.

Turki, F. J., Jdaitawi, M., \& Sheta, H. (2017). Fostering positive adjustment behaviour: Social connectedness, achievement motivation and emotional-social learning among male and female university students. Active Learning in Higher Education, 1-14. https://doi. org/10.1177/1469787417731202

Venezia, A., \& Jaeger, L. (2013). Transitions from high school to college. The Future of Children, 23(1), 117-136. https://doi.org/10.1353/foc.2013.0004

Vinson, D., Nixon, S., Walsh, B., Walker, C., Mitchell, E., \& Zaitseva, E. (2010). Investigating the relationship between student engagement and transition. Active Learning in Higher Education, 11, 131-143. https://doi.org/10.1177/1469787410365658

Wach, F.-S., Karbach, J., Ruffing, S., Brünken, R., \& Spinath, F. M. (2016). University students' satisfaction with their academic studies: Personality and motivation matter. Frontiers in Psychology, 7, 1-12. https://doi.org/10.3389/fpsyg.2016.00055

Woosley, S. A., \& Miller, A. (2009). Integration and institutional commitment as a predictor of college student transition: Are third week indicators significant? College Student Journal, 43, 1260-1271. 
Zavin, K., Eisenberg, D., Gollust, S. E., \& Golberstein, E. (2009). Persistence of mental health problems and needs in a college student population. Journal of Affective Disorders, 117, 108-185. https://doi.org/10.1016/j.jad.2009.01.001

Zimmerman, B. J., Bandura, A., \& Martinez-Pons, M. (1992). Self-motivation for academic attainment: The role of self-efficacy beliefs and personal goal setting. American Educational Research Journal, 29(3), 663-676. https://doi. org/10.3102/00028312029003663

\section{Contact Information}

Gabrielle Wilcox

Werklund School of Education

University of Calgary

gwilcox@ucalgary.ca

Dr. Gabrielle Wilcox is an Associate Professor in the Werklund School of Education at the University of Calgary. She earned a PsyD in 2009 from the Philadelphia College of Osteopathic Medicine School Psychology. She works in the area of School and Applied Child Psychology in the Werklund School of Education and is a member of the Hotchkiss Brain Institute and the Mathison Centre for Mental Health Research and Education. Dr. Wilcox's current research focuses on improving our understanding of how to support student learning and preparation for post-school requirements. Specific areas of research within this include neuropsychology for intervention, mental health in schools, transition planning, and university-level instruction.

Dr. David Nordstokke is an Associate Professor in the Werklund School of Education at the University of Calgary. He received his PhD in 2009 from the University of British Columbia in Measurement, Evaluation, and Research Methodology. He teaches courses in the area of measurement, research design, and statistical analysis. Dr. Nordstokke conducts research across a variety of educational and psychological contexts. Much of

Dr. Nordstokke's current research revolves around youth transition/youth mental health and factors (e.g., resilience) that are related to successful transition and positive life and mental health outcomes. Many projects that Dr. Nordstokke engages in are interdisciplinary and collaborative in nature, and his typical role in this type of research has him focusing on designing sound research studies, selecting valid measurement strategies, and applying statistical models to data that are gathered across a number of disciplines. Another part of Dr. Nordstokke's research is focused on applied methods that include (1) the design of research studies, (2) the collection and statistical analysis of data, and (3) the interpretation and dissemination of results. 